\title{
Life Cycle Thinking in the Use of Natural Resources
}

\author{
C.J. Koroneos ${ }^{*}, 1$, Ch. Achillas ${ }^{1}$, N. Moussiopoulos ${ }^{1}$ and E.A. Nanaki ${ }^{2}$ \\ ${ }^{1}$ Laboratory of Heat Transfer and Environmental Engineering, Aristotle University of Thessaloniki, P.O. Box 483, \\ 54124 Thessaloniki, Greece \\ ${ }^{2}$ University of Western Macedonia, Department of Mechanical Engineering, Bakola and Sialvera, 50100 Kozani, Greece
}

\begin{abstract}
The continuous increase of production and consumption of material in the developed world and the increase of the standard of living of the developing countries leads to the increase of the use of natural resources and the degradation of the environment. Life Cycle Thinking (LCT) is essential to sustainable consumption and production which will impact the use of limited resources. LCT is the process of taking into account in decision making both the resources consumed and the environmental and health pressures associated with the full life cycle of a product. It includes the extraction of resources, production, use, re-use, transport, recycling, and the ultimate waste disposal to provide goods and services and it helps in avoiding shifting the burdens among various life stages of a resource processing. It is important to use the life cycle thinking in analysing products because they may have different environmental impacts at different life cycle stages. It is important to note that some products have very high environmental impacts during the extraction and processing of their original natural resource but they may have minor environmental impacts when they are recycled. A good example is aluminium. The objective of this work is to analyze the importance of the life cycle thinking concept, and show its direct linkage to sustainability.
\end{abstract}

Keywords: Life cycle thinking, sustainability, life cycle assessment.

\section{INTRODUCTION}

Products (goods and services) contribute to various environmental impacts over their life-time. Life Cycle Thinking (LCT) is a concept that accounts for the upstream and downstream benefits and trade-offs. LCT seeks to identify environmental improvement opportunities at all stages across its life cycle, from raw material extraction and conversion, through product manufacture, product distribution, use and fate at the end-of-life stage. Its fundamental aim is to provide a structured and comprehensive approach in support of the overall reduction of product impacts and to help optimize benefits. In this context, LCT is essential to sustainable consumption and production $[1,2]$ as well as, to sustainable development. It is about going beyond the traditional focus on production site and manufacturing processes, in order to include the environmental, social, and economic impact of a product over its entire life cycle [3-5]. The main goals of life cycle thinking are to reduce a product's resource use and emissions to the environment as well as improve its socio-economic performance throughout its life cycle. This may facilitate links between the economic, social and environmental dimensions within an organization and throughout its entire value chain.

The precursors of Life Cycle Thinking emerged in the late 1960s and early 1970s from concerns about limited natural resources, particularly oil. They came in the form of global modelling studies and energy audits. They were

*Address correspondence to this author at the Laboratory of Heat Transfer And Environmental Engineering, Aristotle University Of Thessaloniki, P.O. Box 483, 54124 Thessaloniki, Greece; E-mail: koroneos@aix.meng.auth.gr referred to as Resource and Environmental Profile Analyses (REPA) and Net Energy Analyses. Since the 1970s, needs have changed and techniques have improved. Life Cycle Thinking has become a key complementary tool in policy and decision making, both in government and business.

Life Cycle Thinking is increasingly fundamental in the development of key environmental policies around the world. In the European Union, Life Cycle Thinking is at the heart of a growing number of policies and instruments in areas such as:

- Integrated Product Policy, the Sustainable Consumption and Production and Sustainable Industrial Policy Action Plan, Green Public Procurement, EU Ecolabel, EU Eco-Management and Audit Scheme, Ecodesign, Retail Forum [6-12].

- Waste: Life Cycle Thinking constitutes a key element in the Waste Framework Directive, and it is used to help determine the benefits of different prevention or management options. Life Cycle Thinking is also central to the Thematic Strategy on the prevention and recycling of waste, and the Thematic Strategy on the sustainable use of natural resources [13].

- Eco-innovation and the EU Environmental Technologies Action Plan (ETAP) [14].

Life cycle thinking plays a key role in the concept of pollution prevention in including the whole product life cycle and sustainability. Source reduction in a product life cycle perspective is then equivalent to eco-design principles and the "6 RE philosophy": 
- $\quad$ Re-think the product and its functions. For example, the product may be used more efficiently, thereby reducing energy use and other natural resources.

- Re-duce energy and material consumption throughout a product's life cycle.

- $\quad$ Re-place harmful substances with more environmentally friendly alternatives.

- $\quad$ Re-cycle. Select materials that can be recycled, and build the product so that it is disassembled easier for recycling.

- $\quad$ Re-use. Design the product so parts can be reused.

- Re-pair. Make the product easy to repair so that the product does not yet need to be replaced.

In each life cycle stage there is the potential to lower resource consumption and improve the performance of products [15].

The objective of this work is to identify improvements and to lower the impacts of goods or services (products) at all stage of associated life cycles, from raw material extraction and conversion, product manufacture, through distribution, use and eventual fate at the end-of-life. This is achieved using as a case study the life cycle analysis of a washing machine. The study also aims to take into consideration the environmental impacts of the processes within our direct control, the raw materials used, supply chains, product use, the effects of disposal and the possibilities for re-use and recycling.

\section{KEY PRINCIPLES OF LIFE-CYCLE THINKING}

The product life cycle (Fig. 1) is shown in five distinct phases, all of which interact with the environment. For most products, the life cycle stage of use is far longer than the other stagess, and there may also be periods of storage and non-use between the stages shown. Usually, but not always, these stages will be environmentally benign. It is worth noticing that in the flow-sheet with the feedback loops, the potential for recycling, remanufacturing, reuse, and the strategies (Fig. 1), it becomes obvious that re-use is the strategy that potentially has the lowest environmental impact, merely based on the fact that this involves fewer stages [16]. Each stage uses energy and has a certain environmental impact.

Products may have totally different environmental impacts during different stages of their life cycle [17].
Therefore, the whole of the life-cycle of a product needs to be taken into consideration. For example, some materials may have an adverse environmental consequence when extracted or processed, but be relatively benign in use and easy to recycle. An example is the case for aluminium. On the other hand, a washing machine will create the bulk of its environmental impact during its use phase, mainly due to water and energy consumption which in turn generate water and air pollution, as well as solid waste.

LCT is essential to sustainable consumption and production. It is about going beyond the traditional focus on production sites and manufacturing processes, and expanding it to take into consideration the environmental, social, and economic impact of a product over its entire life cycle, including the consumption and end of use phase. To this extend, the key principles of Extended Producer Responsibility (EPR) and Integrated Product Policy (IPP) are highly promoted.

EPR means that the producers take responsibility for their products from cradle to grave and therefore, they should develop products that have improved performance throughout all stages of the product life cycle as is mentioned in the previous sentence. At each stage of the life cycle, opportunities for improved performance exist.

The goal of IPP is to reduce a product's resource use and its emissions to the environment as well as improve its socioeconomic performance throughout its life cycle. This may facilitate links between the economic, social and environmental dimensions within an organisation and throughout its entire value chain.

In brief, LCT promotes:

- Awareness that strategic selections are not isolated but influence a larger system. For example, one may consider buying office paper. In order to create 50,000 sheets of office paper, it takes 24 trees and 2.3 $\mathrm{m}^{3}$ of landfill space for their final disposal. In this manner, paper made from recycled material needs to be promoted in order to avoid cutting more trees and using more landfill, which in turn leads to achieving sustainability.

- $\quad$ Making choices for the longer term and considering all environmental and social issues associated with those choices. LCT helps decision makers to avoid short term decisions that lead to environmental degradation. As an example, over-fishing might

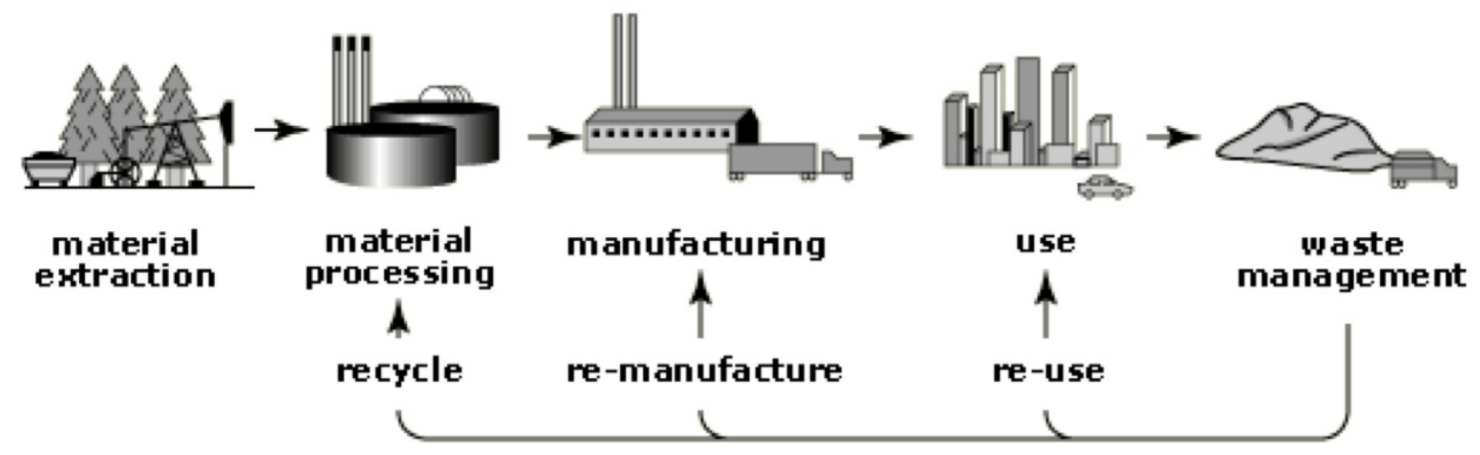

Fig. (1). Life cycle phases of a product. 
provide short-term benefits to people in the fishing business, but would ultimately result to unexpected long-term effects and great loses.

- Improving entire systems, not single parts of systems, by avoiding decisions that fix one environmental problem but cause another unexpected or costly environmental problem. LCT helps to avoid shifting problems from one life cycle stage to another, from one geographic region to another and from one environmental medium (air, water or soil) to another.

- Informed selections, but not necessarily "right" or "wrong" ones. LCT simply helps decision makers to put decisions in context with facts from all parts of the system or life cycle.

LCT applies to the daily decisions made at home and/or workplace; decisions about creating sustainable services and how to develop modern communities. All stakeholders of the community (citizens, businesses, and governments) are finding ways to promote LCT, as well as balance the impacts of their choices. LCT concept can be incorporated into our every day life. For instance, thinking about how industries and homes currently use water and what they release into water systems, are key life cycle considerations. With life cycle information, industrial processes can be redesigned in a way to preserve water quality and improve access to clean water for local people. Another example of environmental considerations, where the whole life cycle of a product needs to be considered is the use of energy and the use of water. As with waste, and issues about replacement solders, such concerns can be analysed particularly effectively using two inter-related techniques:

- The product life cost. In the past this has been primarily a way of assessing "cost of ownership" throughout its life cycle, which includes capital cost, operating costs, servicing and maintenance, and eventually disposal. The concept can however be extended to cover the product's impact on the environment and the energy needed. It is important to take into consideration the fact that all purchased materials have required energy at all their life cycle stages, from the extraction of raw materials to manufacture.

- The product life cycle approach, which takes into account the interrelationship of all life cycle stages, from raw materials extraction to the product manufacture, its use phase and finally the disposal, which however can include recycling for the creation of new raw materials.

In both cases, without consideration of the full life cycle of goods and services (supply/use/end-of-life), the environment suffers - resulting in poorer financial performance and higher potential for reputation damage.

It is obvious that, a life cycle approach to community planning and development can lead to fewer environmental impacts from materials used, construction practices, and waste management, as well as the energy and water used by people living and working in the community.

\subsection{Life Cycle Thinking in Government Policy}

When governments design policy, negotiate voluntary agreements with industry, decide where to invest resources, commission new office buildings, or even purchase paper for offices, LCT can be used. Measuring potential life cycle impacts of decisions can help governments to in their efforts to:

- Inform government programs and help prioritise these programs, based on life cycle information.

- Make policies more consistent among consumers, producers, material suppliers, retailers, and waste managers and also among different policy instruments (e.g. harmonising regulations, voluntary agreements, taxes, and subsidies).

- Purchase products and services which are "environmentally preferable", reduce the impact government operations have on the environment and support regional and global markets for "preferable" products and services.

- $\quad$ Promote pricing products and services to accurately reflect the costs of environmental degradation, health problems, erosion of social welfare, and impacts at other life cycle stages. Such a policy can provide incentives for consumers and businesses to continuously improve the environmental and social performance of products or services, across each stage of the life cycle.

- Introduce take-back systems and reverse logistics networks to establish a recycling-based economy according to the political hierarchy described in the 3Rs concept: (i) reduce, (ii) reuse and (iii) recycle.

\subsection{Life Cycle Thinking in Business}

A product designed with better environmental, social and economic performance across its life cycle may provide benefits to the company, which can be further communicated to its customers. Some businesses elect to use product declarations or other labels to market environmental and social attributes to their customers.

There are international standards for these business-tobusiness communications or "environmental product declarations". Each declaration must be based on a life cycle study and tell the business customer about the life cycle environmental impacts of the component or product being purchased. Among others, declarations exist for building and construction products, refrigerators and other electronic appliances, chemicals, cars, dairy products, etc.

Life cycle thinking that influences product design, strategic planning, procurement, and sales helps businesses:

- $\quad$ Enhance their image and the value of their brands.

- $\quad$ Find new ways for marketing and sales departments to communicate and interact with customers.

- Share life cycle information with suppliers, customers, and waste handlers to identify risks and opportunities for improvement. The risks might relate to the environment, human health, safety, and finance, while opportunities could include growing 
market share, brand image, effective use of materials, and innovation. Together, businesses can find new ways to improve output while optimising their use of time, money, labour, and material input.

\subsection{Put Life Cycle Thinking into Practise}

Life cycle thinking can be put into practice in many ways, involving a number of different "tools". Referring to eco-labels, sustainability indices, and company reports on environmental and social issues helps individual citizens bring life cycle thinking into purchasing decisions. Governments take a life cycle approach to policy making by involving a wide range of stakeholders, life cycle modelling, or new policy approaches (such as Integrated Product Policy). In private sector companies, engineers and designers apply life cycle thinking when designing products and services, via studies based on Life Cycle Assessment, Design-for-Environment programs and management systems oriented toward products or facilities. Quantitative and qualitative tools for mapping life cycles and measuring impacts continue to evolve as more professionals apply life cycle thinking and ask for life cycle information.

\section{LIFE CYCLE ASSESSMENT - A CASE STUDY}

Life Cycle Assessment (LCA) is a process to evaluate the environmental burdens associated with a product, process, or activity by identifying and quantifying energy and materials used and wastes released to the environment; to assess the impact of those energy and materials used and releases to the environment; and to identify and evaluate opportunities to affect environmental improvements. The assessment includes the entire life cycle of the product, process or activity, encompassing, extracting and processing raw materials; manufacturing, transportation and distribution; use, re-use, maintenance; recycling, and final disposal [18].

Life Cycle Assessment has been chosen as the methodology to qualitatively evaluate the environmental loads of the studied bus fleet. Analysis of a system under LCA encompasses the extraction of raw materials and energy resources from the environment, the conversion of these resources into the desired product, the utilization of the product by the consumer, and finally the disposal, reuse or recycle of the product after its service life. The Society of Environmental Toxicology and Chemistry and the International Organization for Standardization (ISO) [19-22] developed in the 1990s the LCA methodology and it was standardized by ISO.

LCA has a holistic approach and seeks to quantify the environmental impacts. It investigates all inputs to the system, together with all outputs, at all stages during the entire life cycle of a product or service. It also categorises environmental impacts in terms of the use of resources, the impacts on human health, and the consequences for the wider world (the so called "ecological consequences").

The life-cycle assessment of a washing machine in terms of the energy and water use, of the contribution to pollution of air and water, and of solid waste is presented in Fig. (2). As expected, most of the environmental impact is during the use phase. With regards to solid waste generation, most of the waste comes from the packaging of the washing machine and the disposal at the end of the product's useful life. However, in practise, these two life cycle phases contribute in total to less than $15 \%$ of the solid waste produced by the washing machine. Nevertheless, it is very important that the packaging of the washing powder or other consumables should also be taken into consideration in the washing machine's life cycle. This illustrates how careful one needs to be when considering the environmental profile of a product. In this sense, every aspect of use should be taken into account, while the "system boundary" should be carefully drawn broadly enough in order to cover the real aspects of environmental burden.

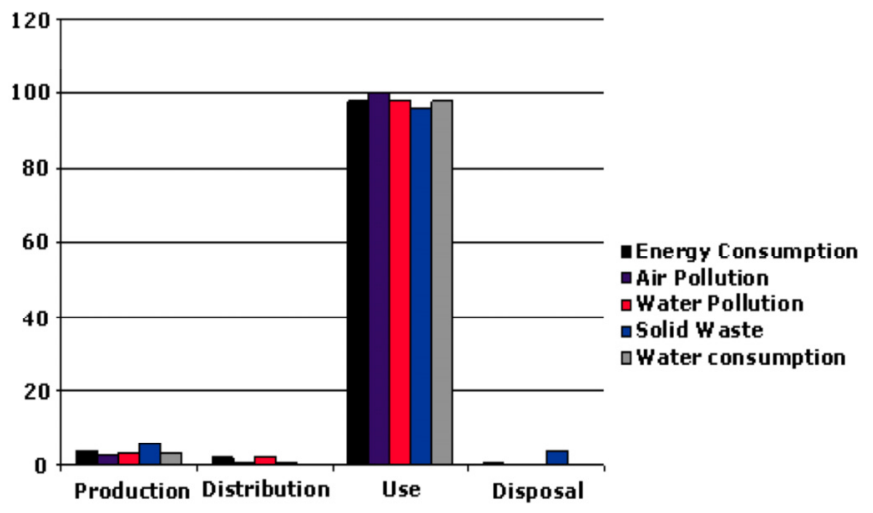

Fig. (2). Life Cycle Assessment of a washing machine.

The framework within which LCA is carried out is shown in Fig. (3). Two main activities are preceded by a vitally important planning phase and followed by extended interpretation, which will normally involve checking the results both against the initial goals and for self-consistency. There are two main activities in an LCA:

(a) The inventory analysis step which describes the emissions that occur and the materials and resources used during the life of a product.

(b) The impact assessment step, which looks at the impacts of emissions and use of resources and raw materials on the environment. In Fig. (4), a general overview of the structure of an impact assessment method is presented. The life-cycle inventory results are related to the so-called "endpoints", which are issues of environmental concern, and by "midpoints", which reflect the mechanism by which the environmental effect takes place.

The LCA methodology takes as its three standard endpoints the damage to human health, to ecosystems and to natural resources. The key problem is what relative weight to place on the three impacts. LCA has a formal way for viewing this, as demonstrated by the "mixing triangle" in Fig. (5). In this triangle each side represents the weighting factor for damage to ecosystem quality, to human health and to energy resources. The summation of all these damages gives the absolute value of $100 \%$. Any point within the triangle represents a mixture of various percentages of each damage category.

\section{CONCLUSIONS}

Sustainability plays a crucial role in transforming both the environment and the society to adapt to the rigorous 


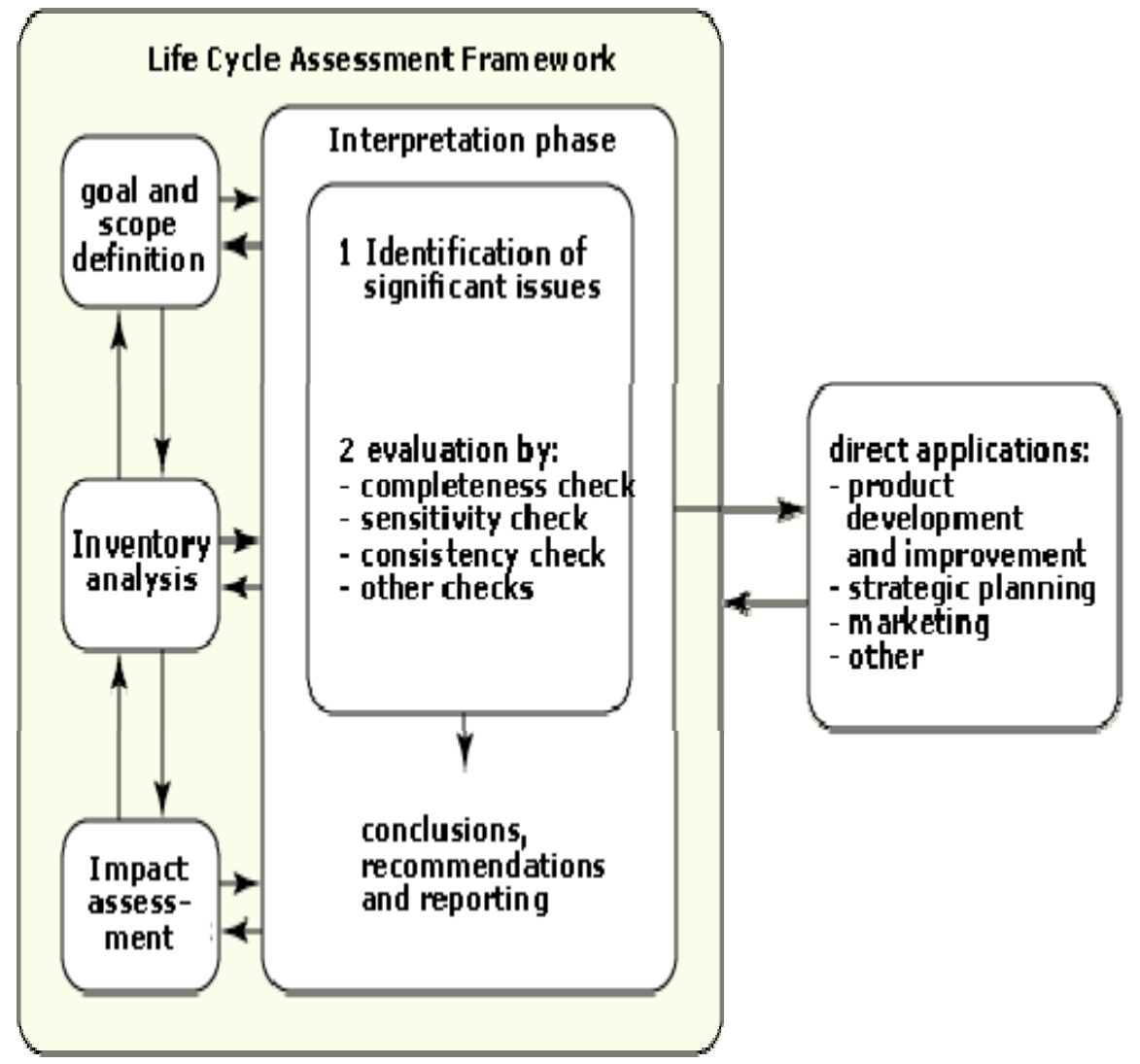

Fig. (3). Life Cycle Assessment Framework.

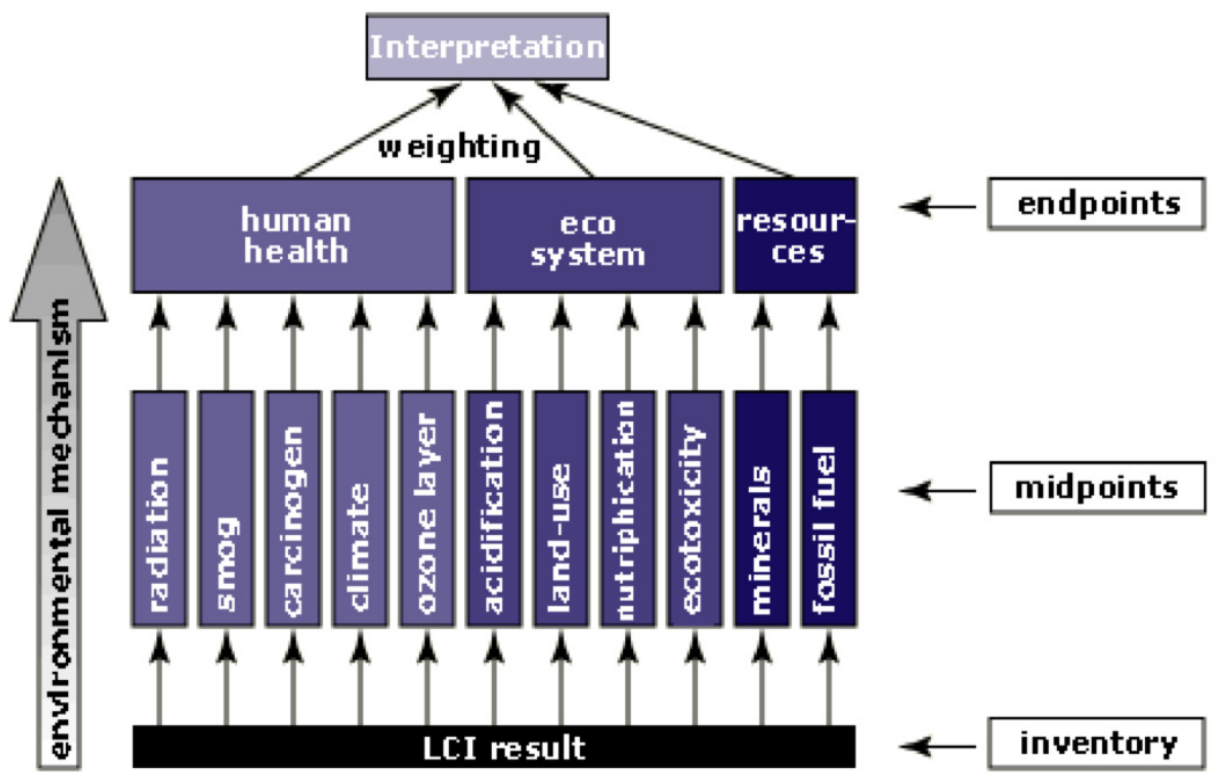

Fig. (4). Structure of impact assessment methodology.

demands of the future. In this context, LCT can promote a more sustainable rate of production and consumption and help people to use their limited financial and natural resources more effectively. Increased value from money invested can be derived by optimising output and getting more benefits from the time, money, and materials used.

Life Cycle Thinking can help identify opportunities and lead to decisions that help improve environmental performance, image, and bring economic benefits of companies. This approach demonstrates to customers that responsibility for reducing environmental impacts is being taken.

Experts from industry, government, and other organisations agree that making life cycle approaches part of the way products are designed and services are developed will help to halt and possibly reverse some of the damaging trends in our communities and environments. It certainly won't solve all environmental problems, but it can help 


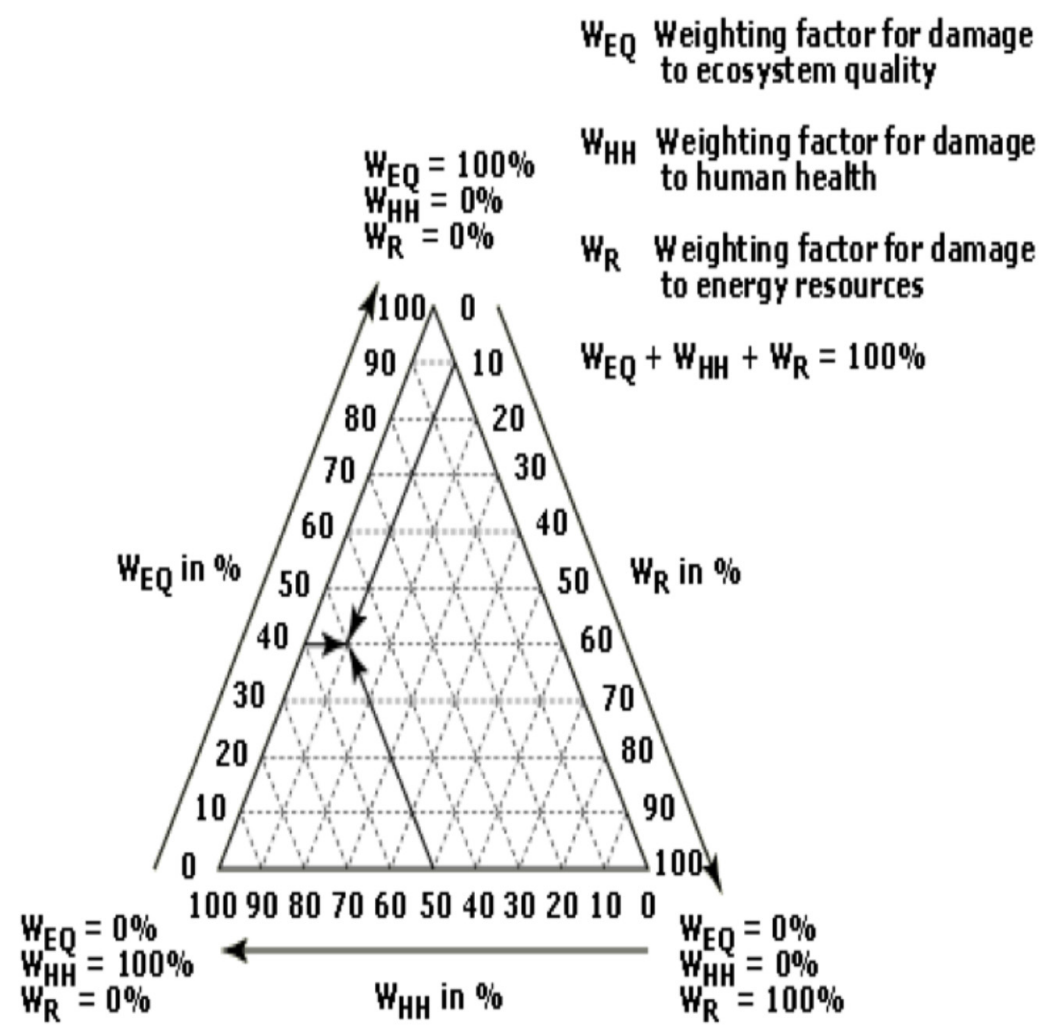

Fig. (5). LCA's “mixing triangle.

towards the direction of finding sustainable ways to tackle most of them.

\section{CONFLICT OF INTEREST}

The authors confirm that this article content has no conflict of interest.

\section{ACKNOWLEDGEMENTS}

Declared none.

\section{REFERENCES}

[1] Hertwich E. Life cycle approaches to sustainable consumption: a critical review. Environ Sci Technol 2005; 39 (13): 4673.

[2] European Commission. Towards a thematic strategy on the sustainable use of natural resources: communication from the commission to the council and the European parliament; Brussels: EC 2003.

[3] UNEP. A business guide to sustainability. Life Cycle Manage 2007.

[4] UNEP. Division of technology, industry, and economics: sustainable consumption \& production branch official website 2009. Retrieved from: http://www.uneptie.org/scp/

[5] UNEP. Why Take A Life Cycle Approach? Nairobi, Kenya: United Nations Publications 2004.

[6] Integrated Product Policy (IPP). Available at: http://ec.europa.eu/ environment/ipp/

[7] The sustainable consumption and production and sustainable industrial policy action plan (SCP/SIP). Available at: http://ec.euro pa.eu/enviro nment/eussd/escp_en.htm

[8] The Ecodesign Directive. Available at: http://ec.europa.eu/enter prise/e co_design
[9] Green Public Procurement (GPP). Available at: http://ec.europa.eu/ environment/gpp

[10] EU Ecolabel. Available at: http://www.ecolabel.eu/

[11] Eco-Management and Audit Scheme (EMAS). Available at http://ec.europa.eu/environment/emas/about/summary en.htm

[12] Retail Forum. Available at: http://ec.europa.eu/environment/industr $\mathrm{y} /$ retail/index_en.htm

[13] Waste Framework Directive. Available at: http://ec.europa.eu/env ironment/waste/framework/index.htm

[14] The EU Environmental Technologies Action Plan (ETAP). Available at: http://ec.europa.eu/environment/etap/

[15] UNEP. Background report for a UNEP guide to life cycle management. US: United Nations Publications 2006.

[16] EIONET. European topic centre on sustainable consumption and production official website. Available at: http://scp.eionet.europa.e u/ on 18.05.2009.

[17] European Commission. Joint Research Centre official website. Available at: http://lct.jrc.ec. europa.eu/ on 11.05.2009.

[18] Society of Environmental Toxicology and Chemistry. Official website. Available at: http://www.setac.org/ on 2009.

[19] ISO 14040. Environmental Management- life cycle assessmentprinciples and framework. Geneva: International Organization for Standardization, 1997.

[20] ISO 14041. Environmental Management- life cycle assessment- goal and scope definition and inventory analysis. Geneva: International Organization for Standardization 1998.

[21] ISO 14042. Environmental Management- life cycle assessment- life cycle impact assessment. Geneva: International Organization for Standardization 2000a.

[22] ISO 14043. Environmental Management- life cycle assessment- life cycle interpretation. Geneva: International Organization for Standardization. 2000b. 